\title{
Efficient Medical Management System for Pharmacist
}

\author{
Ayush Dagar ${ }^{1}$, Sowmya Sista Lakshmi ${ }^{2}$, Neeraj Gupta ${ }^{3}$, Manjeet Kaur ${ }^{4}$, and Rashmi Gupta ${ }^{5}$ \\ ${ }^{1,2}$ Research Scholar, Department of Electrical and Electronics Engineering, Amity University, Gurugram, Haryana, India \\ ${ }^{3,4}$ Assistant Professor, Department of Electrical and Electronics Engineering, Amity University, Gurugram, Haryana, India \\ ${ }^{5}$ Assistant Professor, Department of Computer Science Engineering, Amity University, Gurugram, Haryana, India
}

Correspondence should be addressed to Ayush Dagar; Dagarsaab007@gmail.com

Copyright () 2021 Made Ayush Dagar et al. This is an open access article distributed under the Creative Commons Attribution License, which permits unrestricted use, distribution, and reproduction in any medium, provided the original work is properly cited.

\begin{abstract}
In this era, there is a certain need of keeping all the details digital, with increasing use of technology and need to compete with the outside world one should have some applications where he can store his data. With a great demand of medicines, one could not cope up with this fast world in keeping his data manually. This paper presents an application through python which help us to record data about the medicine. Whenever a person needs, he can change the data, update it, or delete it which help the person to get data about medicines. This application will help to keep record of all the medicines in a good manner and any type of medicine can be searched easily with exact details about that item. It can help to easily update the stock of the medicines available. On seeing any prescription one can search the medicine easily that is it available or not.
\end{abstract}

KEYWORDS- Python, Medicine, Pharmacy, wireless communication.

\section{INTRODUCTION}

Medicine Management System (MMS) is a way by using this can helps to improve accuracy, safety, and efficiency in the medical store. Pharmacist can easily manage inventory, cost, medical safety, update new items etc. with the help of proposed method. The system permits the user to use basic functions like adding, deleting, and updating items. The system will also generate report which displaying the list of products that are entered, their price and the discount. On the arrival of new drugs, it is manually entered into the proposed system. After the selling of drug, the pharmacist may generate report for price, details of the product, batch number, discount, expiry check and availability of the drug in the store. At present, manual system is being utilized in the pharmacy. The pharmacist manually monitors each drug in the store in the previous system. This will cause mistakes as well as enhancement in the workload of pharmacist [1-3].

The prime motive of python project on MMS is to manage the minutiae of Sales, Medicines, Pharmacy, Company Inventory. It manages all the details about the medicine. The proposed system is built at administrative side and the access is only provided by the administrator. The main concern of the proposed system is to create an application program to reduce the manual workload of pharmacist and print customer's medicine bill [4-5].

Medicine management has kept record of bill in filing cabinets. The handling a big pharmacy with records on papers will be a very tedious and hard task. To maintain track of inventories available in the pharmacy is a big challenge to manage manually. The pharmacist has to order drugs to restock the already short of medicine. In addition, ordering of drugs is being carried out manually. Noteworthy amount of time is used for writing the order as the pharmacist needs to go through the stock balance. After getting this application person can update functions of drug and side by side making some discounts and change the number of discounts with respect to availability of the product and view the previous products added or new records [6-7].

Even though the healthcare sector is booming in Covid 19, the pharmacy business is still overlooked by the concerned professionals and is treated as a subsidiary service. Pharmacy business management is very important to the success of the whole healthcare system. Today, even as more than $50 \%$ of the pharmacy business is run by a small number of major retail organizations, pharmacy business faces considerable challenges due to globalization and rising costs. This MMS system is flexible, saves time, money and eco-friendly [8].

\section{PROPOSED METHODOLOGY}

To design maintenance software, the basic requirements would be a powerful Platform, reliable storage capability and a simple interface. All these have been accomplished by Python, a powerful cross-platform language that can run in any device with a Windows or GNU/Linux Interface. When coding an application, there is a requirement for dynamic content fulfilled by SQL.

\section{RESULTS \& DISCUSSION}

Pharmacy Management System data flow diagram (DFD) is often used as a preliminary step to create an overview of the pharmacy without going into great detail, which can later be elaborated. It normally consists of overall application dataflow and processes of the pharmacy process. It contains all of the user flow and their entities such as the flow of Pharmacy, Medicines, Stocks, Bills, Sales, Inventory. All of the below diagrams have been used for the visualization of data processing and structured design of the pharmacy process and working flow.

Figure 1 shows the Zero Level DFD of Pharmacy Management System. It's designed to be an at-a-glance view of Sales, Inventory and Login showing the system as a single high-level process, with its relationship to external entities of Pharmacy, Medicines and Stocks. It should be easily understood by all consumers. 


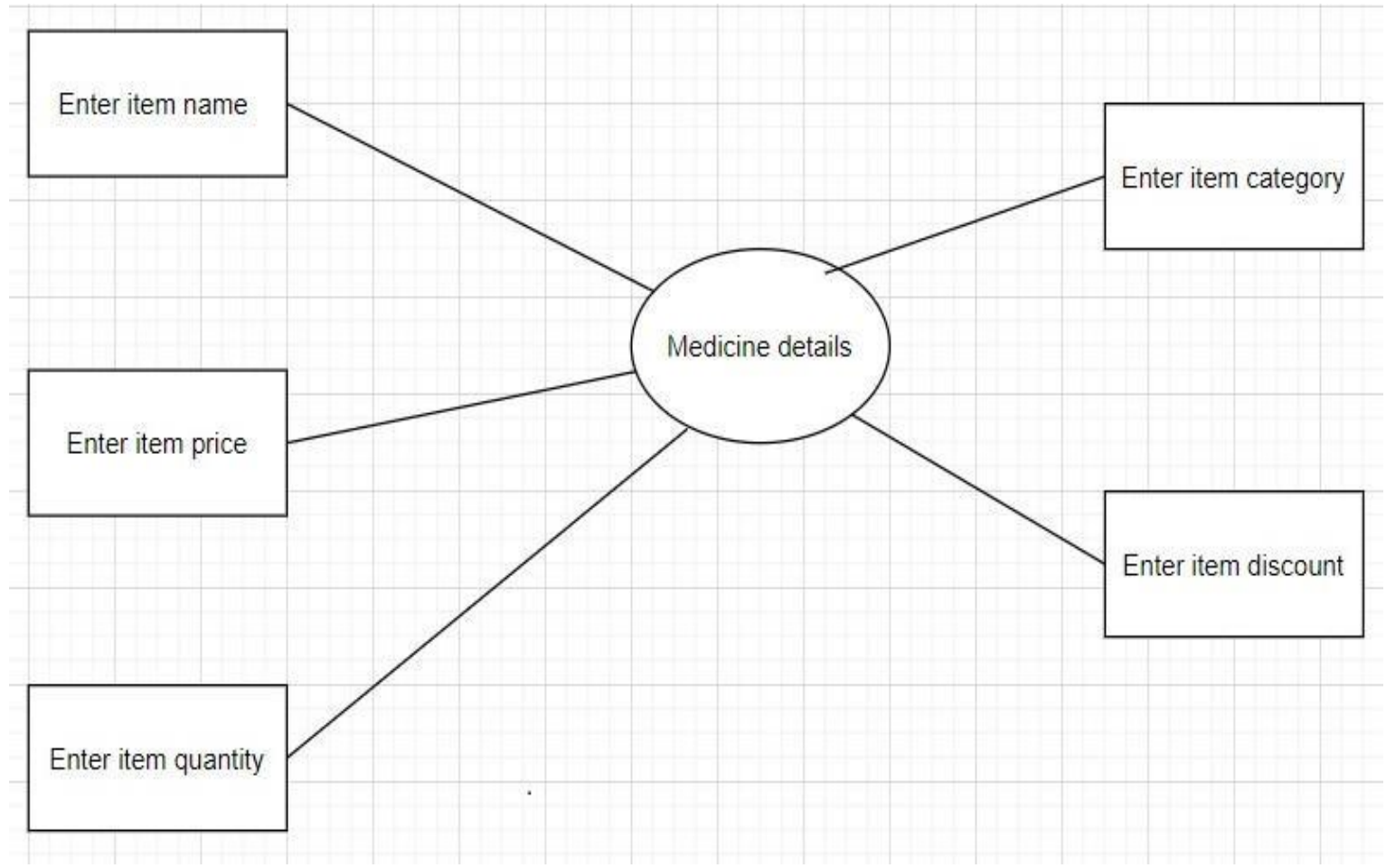

Fig. 1: Flow Chart for main entities

Figure 2 depicts the First Level DFD (1st Level) of Pharmacy Management System which shows how the system is divided into sub-systems (processes).

Main entities and output of First Level DFD (1st Level DFD):

1. Processing Pharmacy records and generate report of all Pharmacy

2. Processing Medicines records and generate report of all Medicines
3. Processing Stocks records and generate report of all Stocks

4. Processing Company records and generate report

5. Processing Sales records and generate report of all Sales

6. Processing Inventory records and generate report of all Inventory

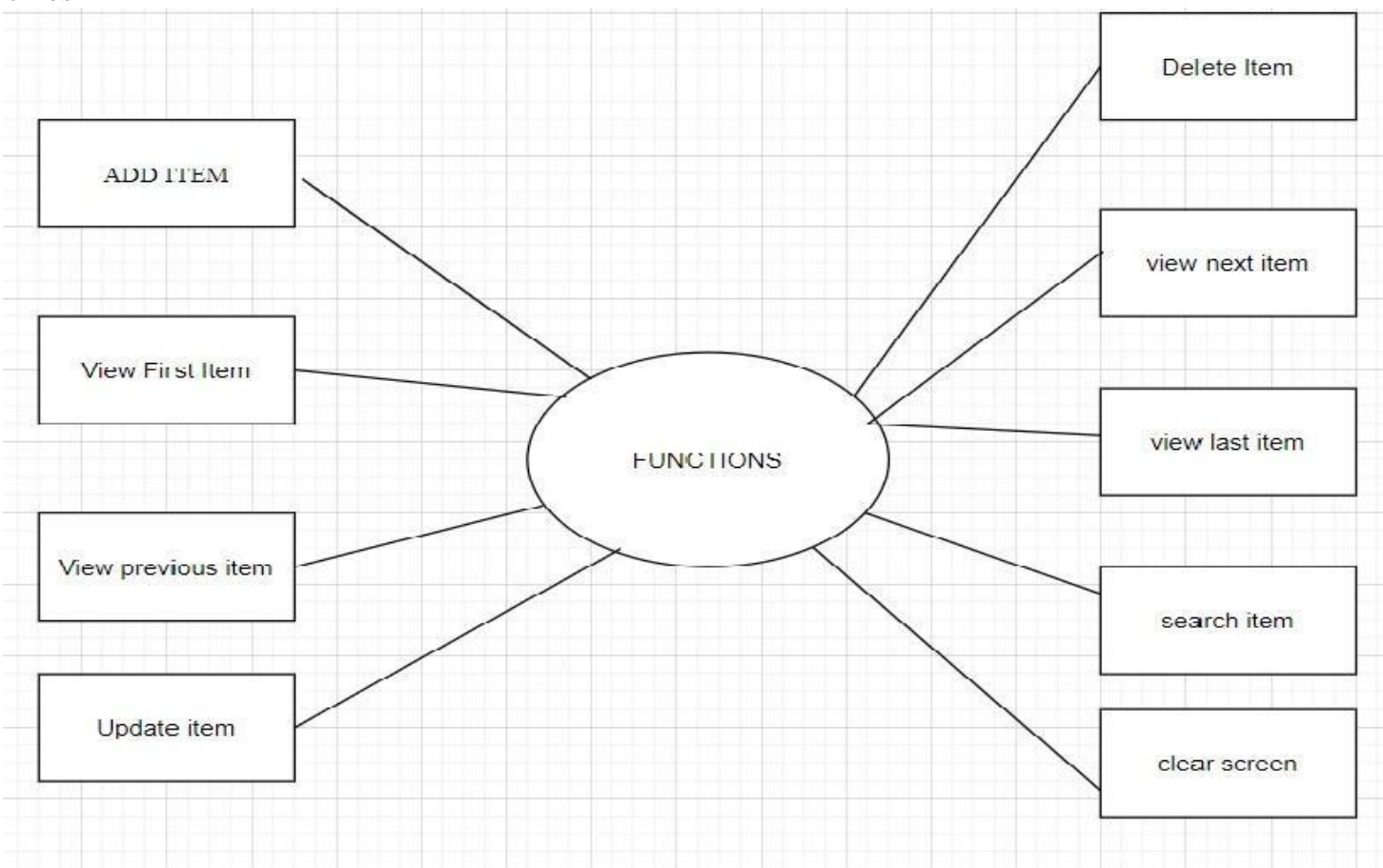

Fig. 2: Flow Chart sub entities 
Figure $3 \& 4$ depicts the main page and menu of MMS.

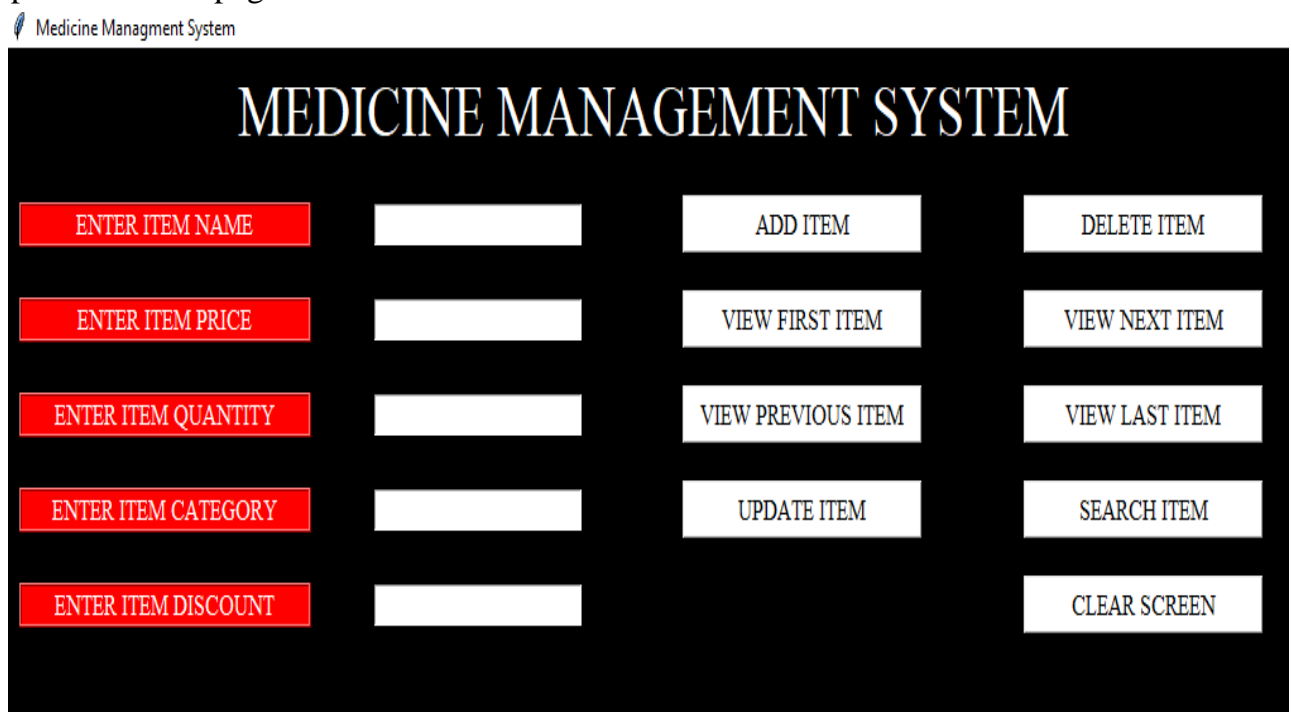

Fig. 3: Main Page

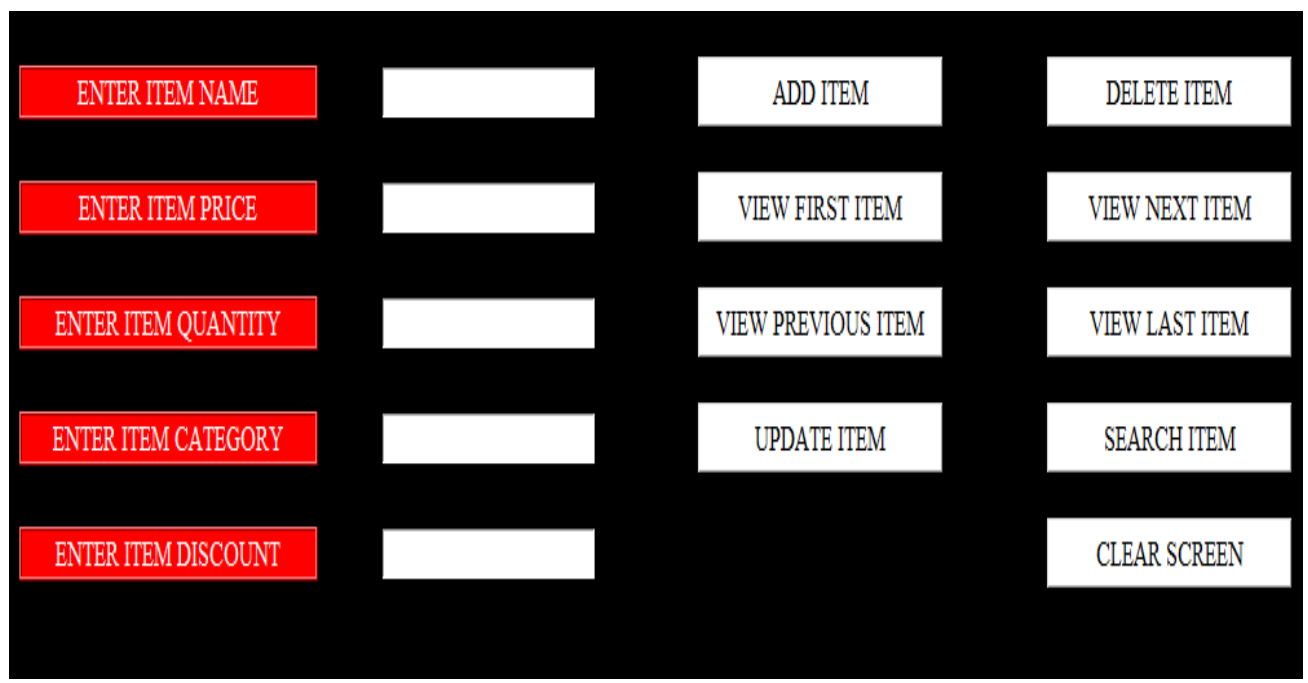

Fig. 4: Menu

Figure 5,6,7 \& 8 highlights the medicine details, database, database after selling the medicine and database after purchasing of new medicine

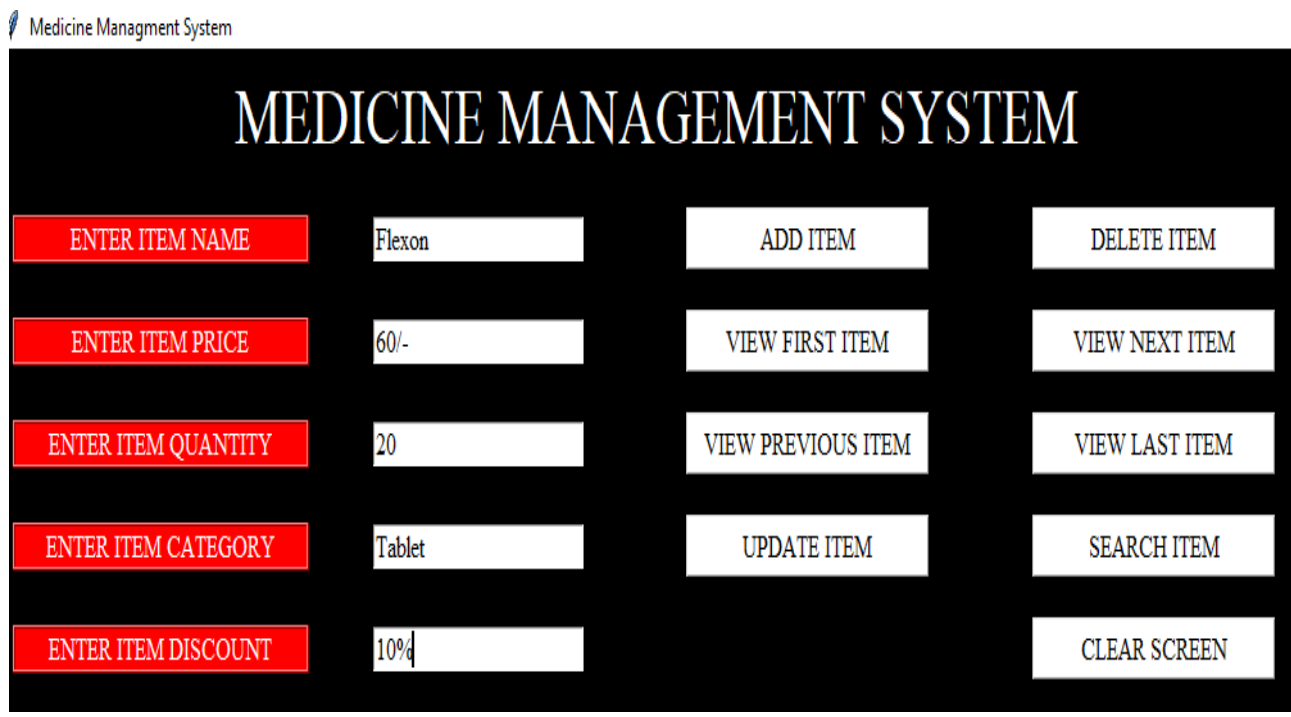

Fig. 5: Medicine Details 
File Edit Format View Help

Flexon 60/- 20 Tablet $10 \%$

Combiflame 80/- 10 Tablet 10\%

Zintac 30/- 50 Tablet 15\%

KeterolDT 70/- 30 Tablet 10\%

Moov 65/- 60 Gel 10\%

Volini 70/- 50 Gel 10\%

Fig. 6: Database

1] *database_proj1 - Notepad

File Edit Format View Help

Flexon 60/- 20 Tablet $10 \%$

Combiflame $80 /-10$ Tablet $10 \%$

KeterolDT 70/- 30 Tablet 10\%

Moov 65/- $60 \mathrm{Gel} 10 \%$

Volini $70 /-50$ Gel $10 \%$

Fig. 7: Database after removing items

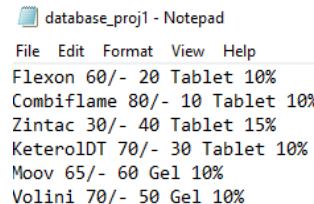

Fig. 8: Database after updated items 


\section{CONCLUSION}

The effective implementation of this software will manage all the needs of MMS. It is capable of providing easy and effective storage of information related to activities happening in the stipulated area. The proposed system will become a milestone in the Covid situation for all pharmacist. In order to allow for future expansion, the system has been designed in such a way that will allow possible modification as it may deem necessary by the pharmacy management, whenever the idea arises.

\section{CONFLICTS OF INTEREST}

The authors declare that they have no conflicts of interest.

\section{ACKNOWLEDGMENT}

The authors of this paper would like to gratefully acknowledge the support provided by Amity school of engineering and Technology. I would like to express our gratitude to Dr. Neeraj Gupta, Dr. Manjeet Kaur, Assistant Professor of Electronics and Communication Engineering Department for providing us with a congenial virtual environment to work in. I would also wish to express our gratitude to HOD, Department of Electronics and communication, ASET for his constant support, encouragement and for his valuable guidance and support in the completion of this paper.

\section{REFERENCES}

[1] A. Dridi, A. Tissaoui and S. Sassi, "The medical project management (MPM) system," 2015 Global Summit on Computer \& Information Technology (GSCIT), 2015, pp. 1-6, doi: 10.1109/GSCIT.2015.7353336.

[2] F. D. Anton and S. Anton, "A Patient Data Management System for Medical Services and Training," 2018 17th International Conference on Information Technology Based Higher Education and Training (ITHET), 2018, pp. 1-6, doi: 10.1109/ITHET.2018.8424792.

[3] Zangana, H.. "Design an Information Management System for a Pharmacy." International Journal of Advanced Research in Computer and Communication Engineering 7 (2018): 52-55.

[4] A. S. Hashim, M. F. M. Yusoff, A. Sarlan, S. Mahamad and S. Basri, "Development of MyHomePharmacy: A personalized family medicine management," 2016 3rd International Conference on Computer and Information Sciences (ICCOINS), 2016, pp. 611-615, doi: 10.1109/ICCOINS.2016.7783285.

[5] Pellegrin K, Chan F, Pagoria N, Jolson-Oakes S, Uyeno R, Levin A. A Statewide Medication Management System: Health Information Exchange to Support Drug Therapy Optimization by Pharmacists across the Continuum of Care. Appl Clin Inform. 2018;9(1):1-10. doi:10.1055/s-00371620262

[6] Kabene, S.M., Orchard, C., Howard, J.M. et al. The importance of human resources management in health care: a global context. Hum Resour Health 4, 20 (2006). https://doi.org/10.1186/1478-4491-4-20

[7] Dash, S., Shakyawar, S.K., Sharma, M. et al. Big data in healthcare: management, analysis and future prospects. J Big Data 6, 54 (2019). https://doi.org/10.1186/s40537-019-0217-0

[8] Monalisa Debbarma, Usha Rani, A Review Study on Pharmaceutical Inventory Management \& Store Keeping Practices of Pharmacy in Rural Hospitals. Indian Journal of Public Health Research \& Development, 11(2), 2020.

\section{ABOUT THE AUTHORS}

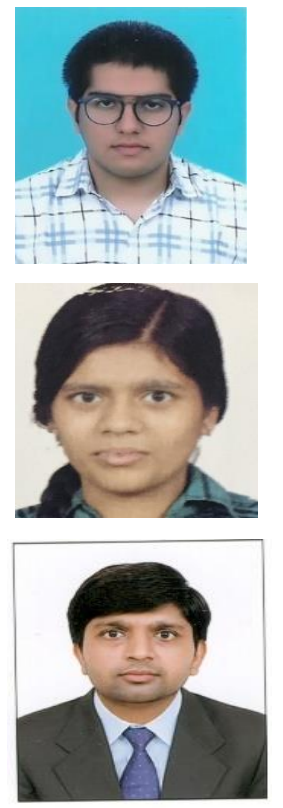

Ayush Dagar is pursuing B.Tech. in Electrical and Electronics Engineering from Amity University Haryana.

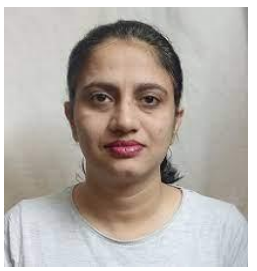

Sowmya Sista Lakshmi is pursuing B.Tech. in Electrical and Electronics Engineering from Amity University Haryana.

Neeraj Gupta received his $\mathrm{PhD}$ degree in Engineering from Amity University Haryana. He is having more than 72 publications in various journals and conferences to his credits. His interests include device modeling, digital VLSI design circuits and ultralow-voltage analog circuits.

Manjeet Kaur received her $\mathrm{PhD}$ degree in Engineering from Amity University Haryana. He is having more than 30 publications in various journals and conferences to his credits. His interests include image processing and control system.

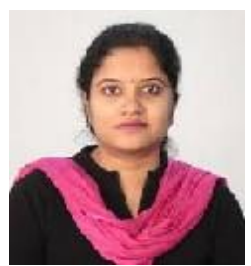

Dr. Rashmi Gupta is currently working as an Assistant Professor, in CSE department in Amity School of Engineering and Technology, Amity University Haryana. She has total 9.5 years of teaching and research experience. She has published more than 20 papers in various international journals as well as in conferences of good repute. Her research area is Artificial intelligence, Software Engineering, and algorithms. 